\title{
BUILDING DAMAGE IN THE REEFTON AREA
}

\author{
D. I. D. Bird**, S. C. Gentry*, J. P. Hollings*
}

This paper covers building damage occurring in the area between Inangahua Landing (approximately 14 miles north of Reefton,) Reefton itself and down to Totara Flat (approximately 16 miles south-west of Reefton). Reefton is an old mining town on the upper reaches of the Inangahua River some 20 miles above and to the south of Inangahua itself. It is administered as a County Town. The township of Reefton and in fact practically all structures in the area were situated on alluvial river flats, a fact of some significance in the damage observed. Almost without exception every property owner in the area suffered some damage。 The degree of damage was greatest in the Rotokehu area, north of Reefton, but the extent of damage was of course greatest in the Reefton Township. There were in all some 665 claims against the Earthquake and War Damage Commission totalling some $\$ 205,000$ 。 There were few structures of significance and most buildings in the area were old or very old, but a number of new structures have been built in the last few yearso. On account of age and arrears of maintenance many buildings in the area were in poor condition before the earthquake, although their age indicates they must have survived previous earthquakes.

There were few claims of any size in the area. In Reefton itself for example there were only twelve claims for more than $\$ 1,000$ (including contents of buildings). There was one claim between $\$ 2,000$ and $\$ 3,000$ and two claims between $\$ 3,000$ and $\$ 4,000$. The three largest claims were for the hospital and two hotels. These figures do not of course include government buildings which were not insured. (The Post Office was severely damaged and was subsequently demolished).

Structural damage was limited, and it is convenient to separate old buildings from the newer ones.

\section{Old structures}

These were predominantly of timber construction, with some of mixed timber and masonry, and a very few of masonry proper.

There were no total collapses of any structures of size. Damage was generally limited to separation of masonry and timberwork and to masonry cracking. Typical examples of the former were a store where mass concrete partition walls separated up to 1 " from the adjoining timber work. Masonry cracking was severe in the solid brick Post Office (Photos 1 and 2)。

In Reefton township only one dwelling was damaged beyond economic repair. This was a double brick building, the outer walls of which partially collapsed。

The Cronadun Hotel, an old 2 storey timber frame structure, some 8 miles north of Reefton, suffered structural damage. The building has 2 later single storey additions, one on continuous concrete footings and one on concrete piles. The 2 storey portion on old wooden piles moved

+ Consulting Engineer, Wellington.

+ Insurance Assessor, Dunedin。 
relative to the single storey portions up to $3^{\prime \prime}$. The timber piles show evidence of rocking some $3^{\prime \prime}$ one way and the other, but they were practically non-existent $3^{\prime \prime}-6^{\prime \prime}$ below ground level (Photo 3). Surprisingly there was little evidence of settlement in a wet alluvial soil.

\section{New structures}

New structures built according to accepted principles of earthquake resistant design were generally completely unharmed, but in some cases there was evidence of foundation movements.

The new classroom block at Sacred Heart School built recently in reinforced blockwork was unharmed as was the new town bridge across the Inangahua River. Some new structures did however suffer damage, and most contained doubtful practice in one form or other.

At Cronadun, 7 miles north of Reefton, an Abattoir built on an alluvial flat with a high water table suffered collapse of an unreinforced blockwork lean-to in course of construction (see photos 4 and 5 ). This structure had been founded on a reinforced concrete footing which was not continued across two doorwayso Complete separation of the structure occurred across a line joining the two doors and the two halves moved apart bodily some $2^{\prime \prime}$. This was notwithstanding concrete bands provided over the doors and at eaves level. No part of the structure actually collapsed but much of it will require rebuilding.

A sawnill, 2 miles north of Reefton, a recently completed portal frame structure, with a timber mezzanine floor on concrete piles and jackstudding, suffered minor damage. The large concrete footings to the saws moved in the ground, putting the saws out of alignment, as did several of the individual concrete piles. Round all the footings, the alluvial soil could be seen to have been loosened, and some minor motor foundations posed vibration problems after the quake when the motors were run. The continuous footing to the main portal frame structure however showed no signs of distress.

At the Reefton Secondary School concrete block veneer panels (in recent timber frame additions of substantial area) suffered minor cracking and offsets. (The remaining timber sheathed portions of this structure were unmarked). Some concrete block veneer actually fell off a motel unit and inspection revealed that although there were the correct number of ties, these were only held to the framing with $14 \mathrm{~g}$ staples which had pulled out (Photo 6).

A relatively new floor in a motor car sales showroom showed considerable damage due to movements in the underlying gravel soilso The slab was badly cracked, and at construction joints differential movements

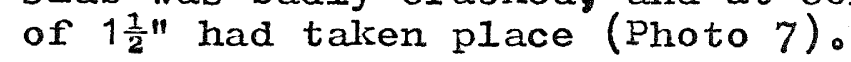

Apart from the structural damage described, the type of damage which seemed to predominate, in descending order of frequency was:

(a) Chimneys and associated damage to roofs and ceilings. Many chimneys fractured at the roofline。

(b) Plumbing, especially hot water cylinders and to a lesser degree W.C. pans. In the rural area north of Reefton there was fairly frequent damage to water tanks mounted on wooden stands. 
(c) Timber piles and flooring (either loosening or settlement). In many cases the damage to flooring was merely an aggravation of a pre-existing condition.

(d) Fireplaces and hearths。

(e) Windows and other glassware, wallpaper in the comer of rooms, etc。

Overall the damage observed was typical of that caused by moderated shaking to structures of the type concerned, perhaps aggravated by the alluvial soils on which they were founded, and more particularly so if any filling was involved. 


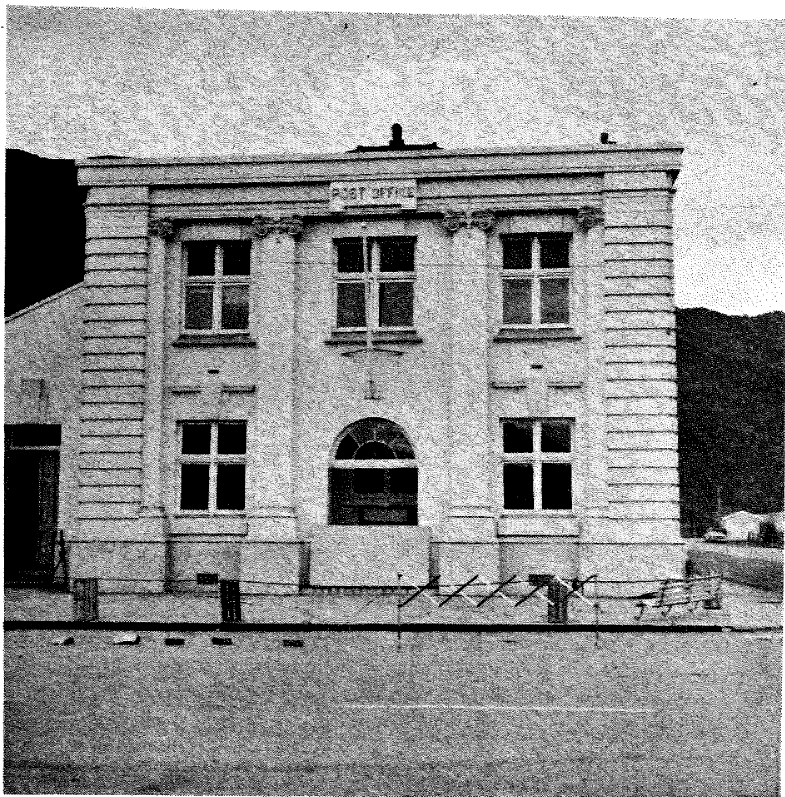

Fig. 1. Reefton Post Office building, with unreinforced brick masonry walls

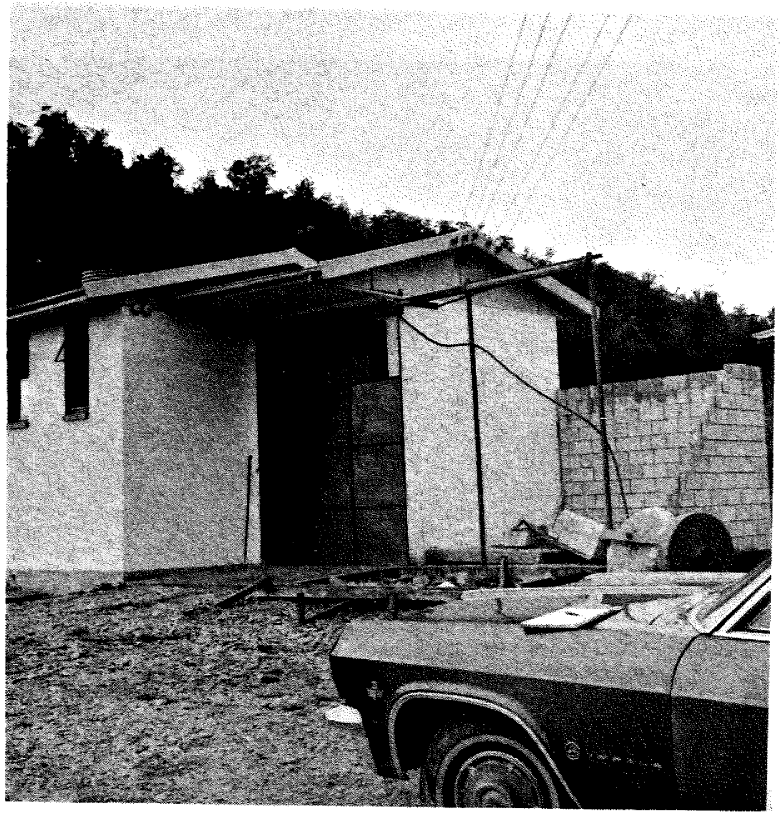

Fig. 4. Abattoir near Cronadun

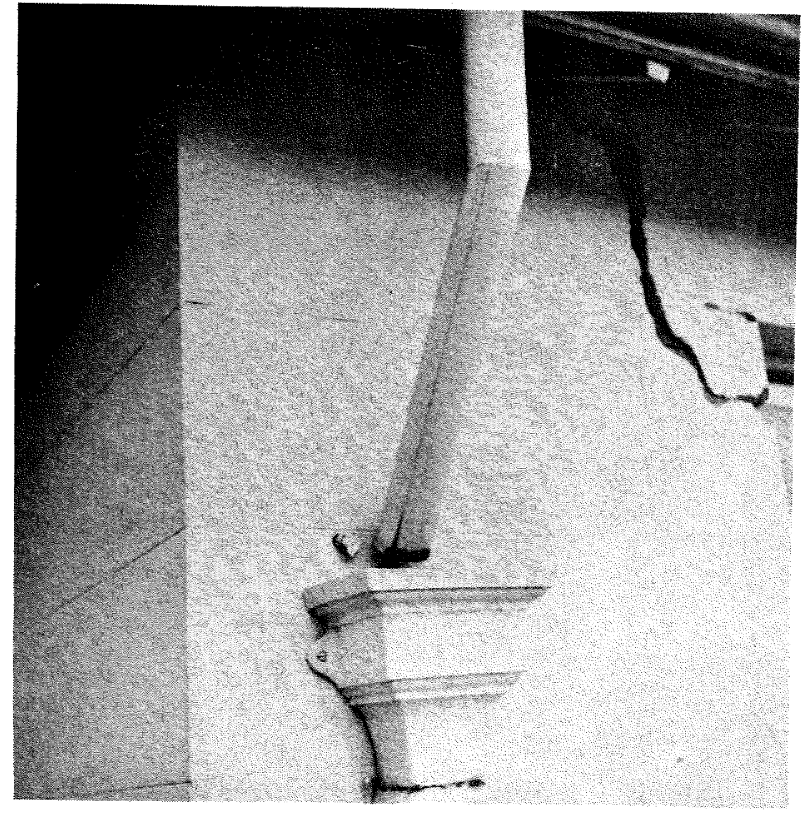

Fig. 2. Reefton Post Office, heavy cracking at a window head

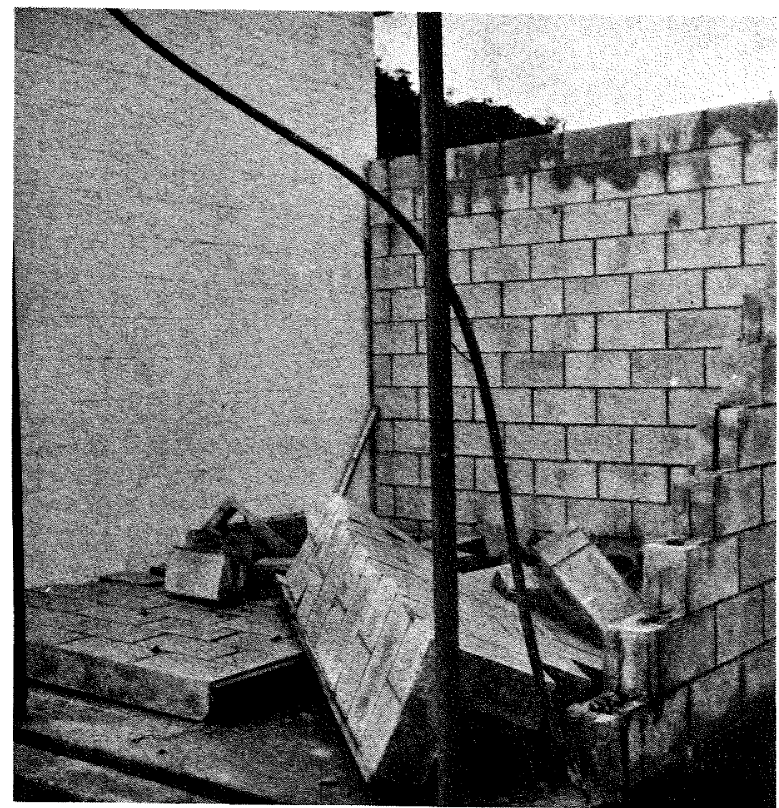

Fig. 5. Abattoir near Cronadun, partial collapse of unreinforced concrete blockwork lean to structure 


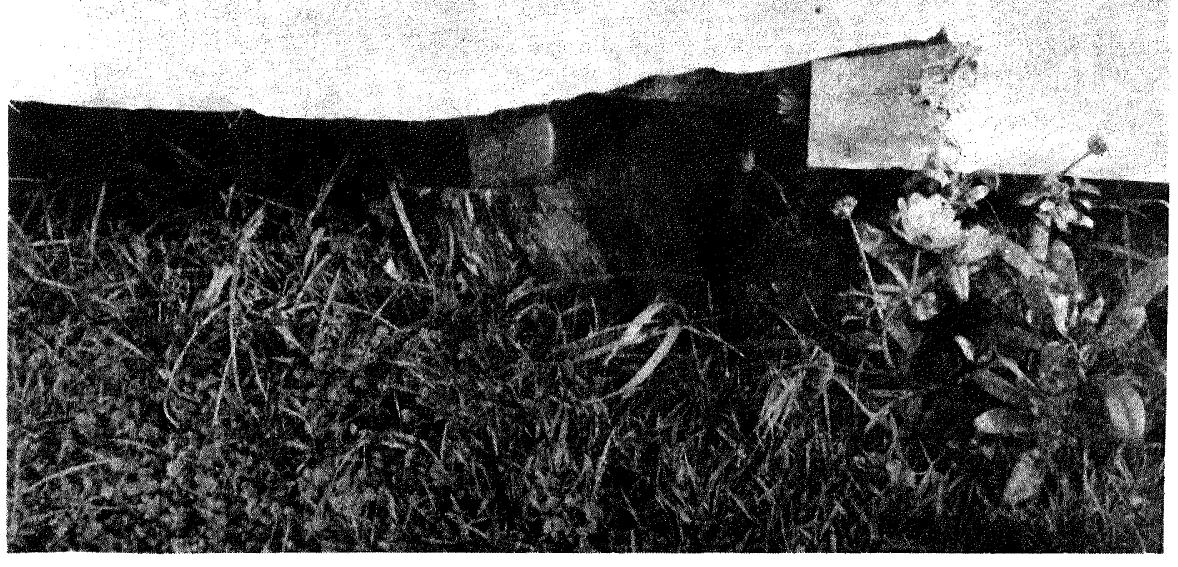

Fig. 3. Cronadun Hotel. Pile rocked some $3^{\prime \prime}$ to 4 " leaving a gap in the ground, evident at the right side of the pile

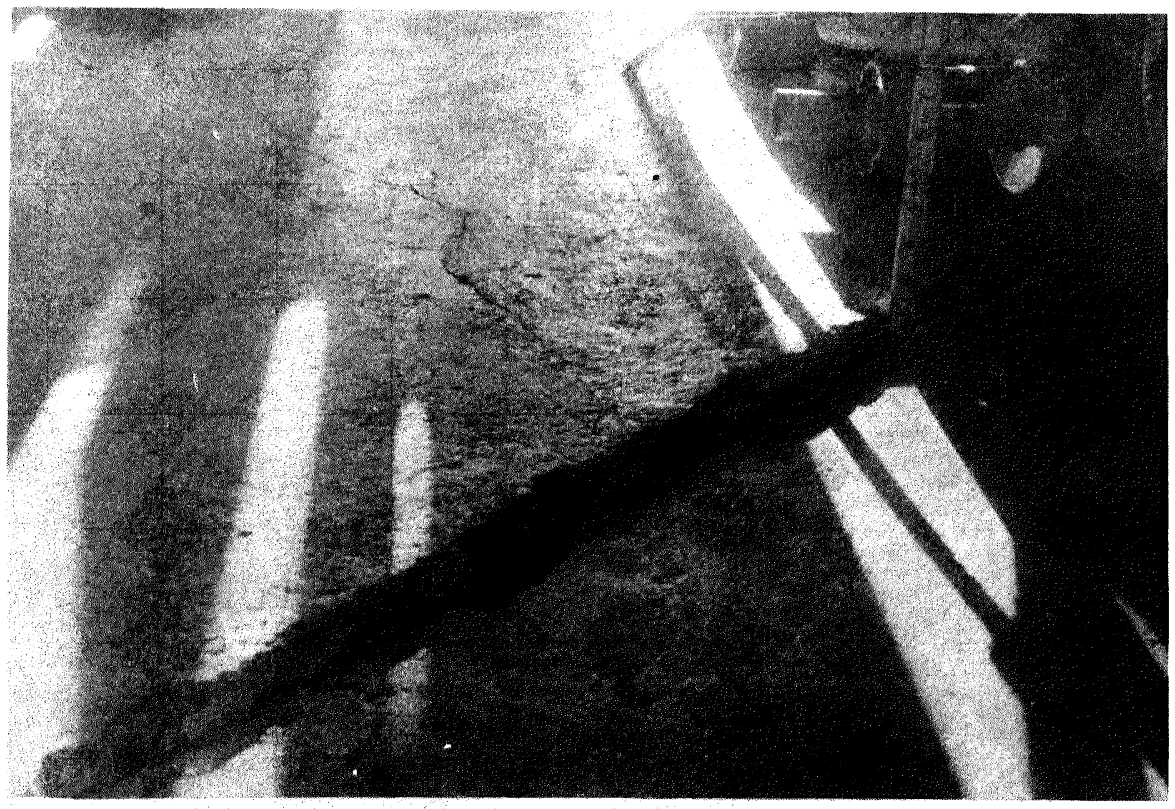

Fig. 7. Motor garage building in Reefton. Differential movement of floor slab at construction joint, in shw

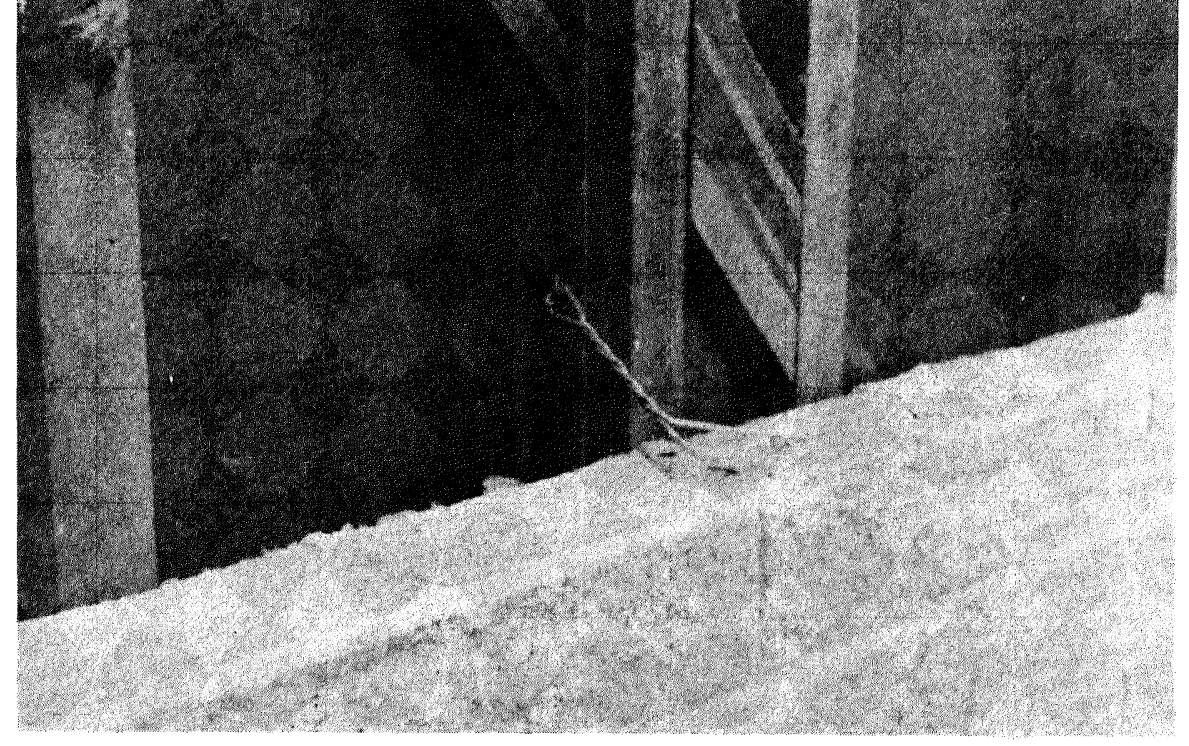

Fig. 6. Motel in Reefton. Staples of 14 gauge pulled out allowing blockwork veneer to separate from the structure 